\title{
Childhood multidrug-resistant tuberculosis in the European Union and European Economic Area: an analysis of tuberculosis surveillance data from 2007 to 2015
}

Csaba Ködmön¹, Martin van den Boom², Phillip Zucs¹, Marieke Johanna van der Werf1

1. European Centre for Disease Prevention and Control, Stockholm, Sweden

2. Joint Tuberculosis, HIV and Viral Hepatitis Programme, World Health Organization, Regional Office for Europe, Copenhagen, Denmark

Correspondence: Csaba Ködmön (csaba.kodmon@ecdc.europa.eu)

Citation style for this article:

Ködmön Csaba, an den Boom Martin v, Zucs Phillip, van der Werf Marieke Johanna. Childhood multidrug-resistant tuberculosis in the European Union and European Economic Area: an analysis of tuberculosis surveillance data from 2007 to 2015. Euro Surveill. 2017;22(47):pii=17-00103. https://doi.org/10.2807/1560-7917. ES.2017.22.47.17-00103

Background: Confirming tuberculosis (TB) in children and obtaining information on drug susceptibility is essential to ensure adequate treatment. We assessed whether there are gaps in diagnosis and treatment of multidrug-resistant (MDR) TB in children in the European Union and European Economic Area (EU/ EEA), quantified the burden of MDR TB in children and characterised cases. Methods: We analysed surveillance data from 2007 to 2015 for paediatric cases younger than 15 years. Results: In that period, $26 \mathrm{EU} /$ EEA countries reported 18,826 paediatric TB cases of whom 4,129 (21.9\%) were laboratory-confirmed. Drug susceptibility testing results were available for 3,378 (17.9\%), representing $81.8 \%$ of the confirmed cases. The majority $(n=2,967 ; 87.8 \%)$ had drug-sensitive TB, 249 (7.4\%) mono-resistant TB, 64 (1.9\%) polyresistant TB, 90 (2.7\%) MDR TB and eight (0.2\%) had extensively drug-resistant (XDR) TB. MDR TB was more frequently reported among paediatric cases with foreign background (adjusted odds ratio $(\mathrm{aOR})=1.73$; $95 \%$ confidence interval $(95 \% \mathrm{Cl}): 1.12-2.67)$ or previous TB treatment (aOR: 6.42; 95\% Cl: 3.24-12.75). Successful treatment outcome was reported for 58 of 74 paediatric MDR TB cases with outcome reported from 2007 to 2013; only the group of 5-9 years-olds was significantly associated with unsuccessful treatment outcome (crude odds ratio $(\mathrm{cOR})=11.45 ; 95 \% \mathrm{Cl}$ : 1.24-106.04). Conclusions: The burden of MDR TB in children in the EU/EEA appears low, but may be underestimated owing to challenges in laboratory confirmation. Diagnostic improvements are needed for early detection and adequate treatment of MDR TB. Children previously treated for TB or of foreign origin may warrant higher attention.

\section{Introduction}

Multidrug-resistant tuberculosis (MDR TB) is a major challenge in the fight to end the global tuberculosis (TB) epidemic [1]. Of 10.4 million incident cases of TB and 1.8 million deaths from TB estimated for 2015 globally, ca 480,000 cases and ca 190,000 deaths were attributed to MDR TB [2]. An estimated 1.0 million incident cases of TB and 170,000 deaths from TB occurred in children [2]. The estimated proportion of MDR TB among children with TB in 2014 was $2.9 \%$ (range: 2.7-3.1) [3]. In the European Union (EU) and European Economic Area (EEA), children under 15 years of age accounted for 2,415 (4.2\%) of 57,136 TB cases notified in 2015, which corresponded to a notification rate of 3.0 per 100,000 population [4]. Data on drug resistance patterns in children in the EU/EEA have, to our knowledge, not been analysed in the past.

Despite the availability of modern technologies such as nucleic acid amplification tests, diagnosis of TB in children is challenging. Clinical diagnosis is not standardised $[5,6]$, and the traditional and molecular diagnostic methods lack sensitivity in children, while serological methods lack specificity [6]. Also, since most laboratory tests for TB are done on sputum and children most often have paucibacillary disease, it is not easy to identify Mycobacterium tuberculosisbacilli or DNA in their sputum samples. Furthermore, specimens for culture and drug susceptibility testing are often difficult to obtain, particularly from the youngest (younger than 3 years) who cannot expectorate sputum $[7,8]$. In such cases, hospital clinicians may obtain specimens through gastric aspirates, induced sputum and/or nasopharyngeal aspirates, and bronchoalveolar lavage [6]. Moreover, in children, M. tuberculosis tends to spread from the lungs to the regional hilar 


\section{FIGURE 1}

Drug susceptibility testing coverage and percentage of multidrug-resistant tuberculosis among children in 26 European Union and European Economic Area countries reporting case-based drug susceptibility data, 2007-2015 $(\mathrm{n}=18,826)$

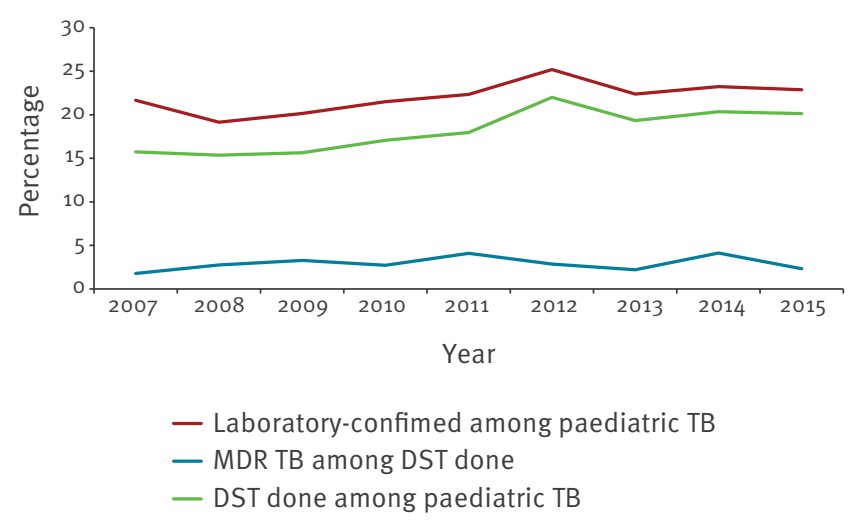

DST: drug susceptibility testing; MDR: multidrug-resistant; TB: tuberculosis.

and mediastinal lymph nodes as well as to other parts of the body; therefore, extrapulmonary TB, which is more difficult to diagnose than pulmonary $T B$, is more common than in adults [7]. Despite rigorous specimen collection and laboratory techniques, culture confirmation of pulmonary TB succeeds in no more than $40 \%$ of children [6] and even less frequently for extrapulmonary TB $[8,9]$. Because conventional drug susceptibility testing (DST) is performed by phenotypic methods that depend on culture confirmation, DST results are often lacking in children $[6,10]$.

First-line drugs for treating active TB disease in adults and children are isoniazid, rifampicin, pyrazinamide and ethambutol [11-13]. These drugs are generally better tolerated by children than adults [14]. Since DST results are often not available for children, they risk receiving suboptimal treatment and facing an unfavourable treatment outcome [15].

The published literature lacks robust epidemiological information on diagnosis and treatment of MDR TB in children, which may be due to challenges in diagnosis and under-detection [16]. The little evidence available largely consists of case reports or case series reports, mainly from countries outside Europe [17-22]. Therefore, we aimed to describe the burden of and identify factors associated with MDR TB in children and to assess whether there are gaps in diagnosis and treatment of MDR TB in children.

\section{Methods}

The European Centre for Disease Prevention and Control (ECDC) has been collecting case-based TB surveillance data from EU and EEA countries since 2007 and storing them in a common database, the European Surveillance System (TESSy). Designated national surveillance institutions are responsible for data reporting to ECDC and data validation. The detailed data collection methods, definitions and figures on data completeness are described elsewhere [4].

TB cases were defined according to the case definition published by the European Commission [23], and all confirmed, probable and possible cases were included in the analysis. Liechtenstein only reported case-based TB surveillance data for 2007 and Croatia for 2012, 2013, 2014 and 2015; both countries were therefore excluded from the analysis. France, Italy and Spain are not reporting case-based DST data to ECDC and were also excluded. Surveillance data reported by the remaining $26 \mathrm{EU} / \mathrm{EEA}$ countries and covering the period from 2007 to 2015 were extracted from the TESSy database on 10 October 2016. Greece did not report treatment outcome after 12 months for the years 2007 to 2012 and was therefore excluded from the treatment outcome analysis.

TB cases younger than 15 years were considered paediatric TB cases. MDR TB was defined as resistance to at least isoniazid and rifampicin and extensively drugresistant (XDR) TB as resistance to at least isoniazid and rifampicin, any fluoroquinolone and any of the three second-line injectable drugs amikacin, capreomycin and kanamycin. DST was considered completed if a TB case was laboratory-confirmed according to the EU case definition (culture-positive or microscopy-positive for acid-fast bacilli and nucleic acid-positive for TB) [23] and resistance data for at least isoniazid and rifampicin were available. Cases with both pulmonary and extrapulmonary TB were classified as pulmonary TB. For the majority of countries, geographic origin was considered foreign if place of birth was outside the reporting country. For Austria, Belgium, Greece, Poland and Hungary from 2010 onwards and for Malta in 2010, foreign origin was defined as a citizenship other than that of the reporting country. For cases with TB sensitive to isoniazid or rifampicin, treatment outcome data (success, failed, died, lost to follow-up, still on treatment) were collected 12 months after the start of treatment. For MDR and for XDR TB cases, treatment outcome was collected 24 months and 36 months after start of treatment, respectively. Treatment outcome was considered successful if a case was cured or had completed treatment.

We analysed paediatric TB cases by laboratory confirmation and drug resistance (susceptible, monoresistant, polyresistant, MDR (excluding XDR) and XDR), age group ( $0-4,5-9$ and 10-14 years), sex, origin (native, foreign), TB site (pulmonary, extrapulmonary), treatment history (new or previously treated case) and treatment outcome. Susceptible, monoresistant and polyresistant TB cases were considered as non-MDR TB cases.

Factors associated with laboratory confirmation, multidrug resistance and treatment outcome were identified 


\section{FIGURE 2}

Number of and percentage paediatric multidrug-resistant tuberculosis cases among laboratory-confirmed paediatric TB cases with drug susceptibility testing results, European Union and European Economic Area, 2007-2015 (n = 3,378)

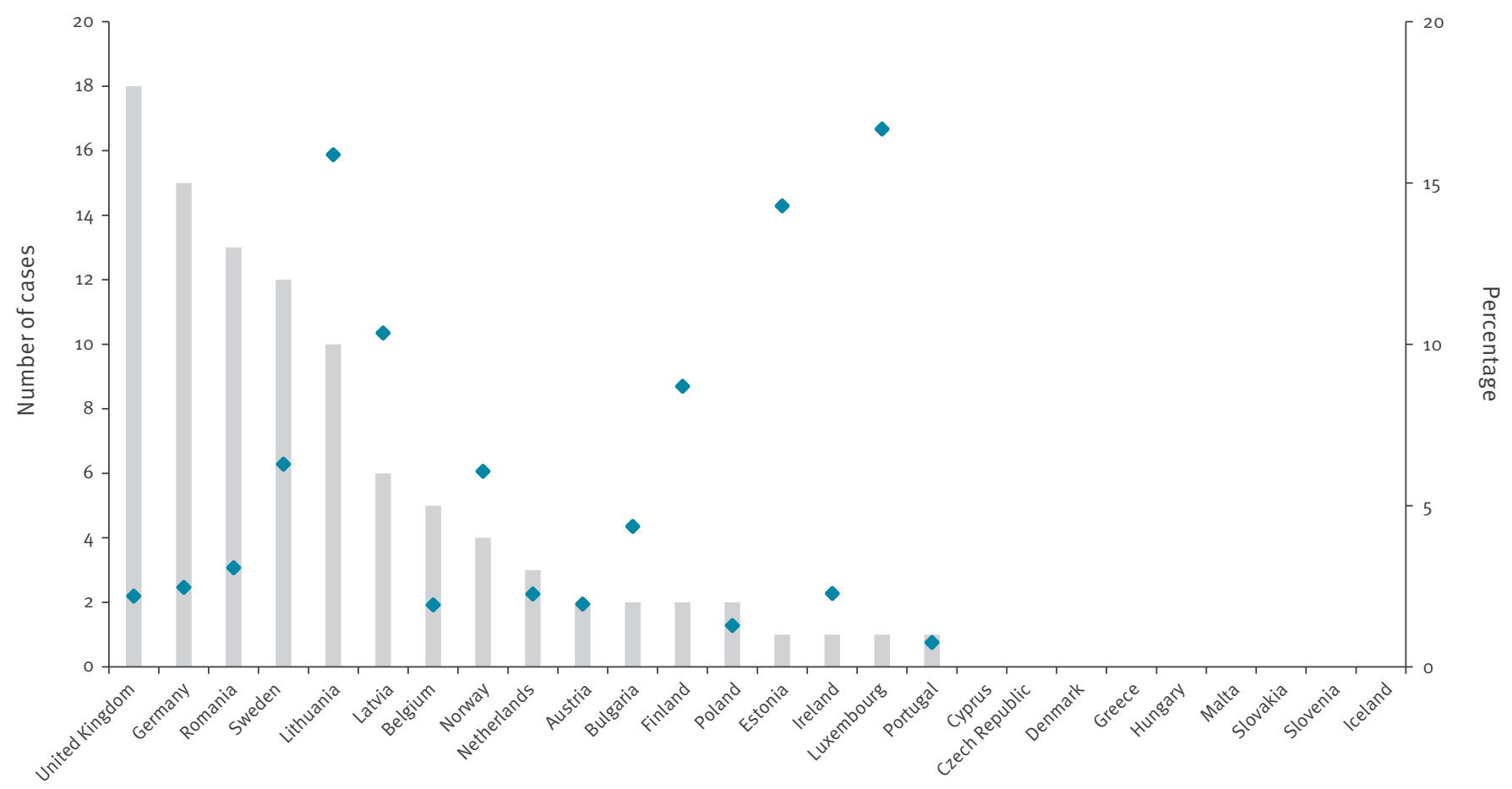

Paediatric MDR TB cases

- Percentage of MDR TB cases among paediatric TB cases with DST results

DST: drug susceptibility testing; MDR: multidrug-resistant; TB: tuberculosis.

by univariate analysis. If for any univariate association, the $p$ value was less than or equal to 0.1 by chi-squared test, the variable was included in a multivariable logistic regression model applying backward elimination based on maximum likelihood estimates. Statistical associations were expressed as odds ratios (OR) with $95 \%$ confidence intervals $(\mathrm{Cl})$. Differences were considered statistically significant if $p<0.05$ as determined by chi-squared test. Statistical analysis was performed using STATA 14 software (StataCorp, Texas, United States (US)).

\section{Results}

From 2007 to $2015,18,826$ paediatric TB cases were reported in the $26 \mathrm{EU} / \mathrm{EEA}$ countries included in this study. The average percentage of paediatric TB cases among all notified TB cases was $3.7 \%$ over the years (range: $3.5-3.8$ ).

Among the 18,826 notified paediatric TB cases, 4,129 (21.9\%) were laboratory-confirmed, of whom 894 (21.6\%) had a positive NAAT test and DST results were available for 3,378 (17.9\%), representing $81.8 \%$ of all laboratory-confirmed paediatric TB cases. The majority of cases for whom DST had been done $(n=2,967$; $87.8 \%)$ had drug-sensitive TB, 249 (7.4\%) had monoresistant TB, 64 (1.9\%) polyresistant TB, 90 (2.7\%) MDR
TB (excluding XDR TB), and eight (0.2\%) were diagnosed with XDR TB.

The percentage of MDR TB among paediatric TB cases with available DST results ranged between $1.8 \%$ and $4.1 \%$ during the study period, while the DST coverage among all paediatric TB cases was between $15.4 \%$ and $22.0 \%$ in the different years (Figure 1). The trend of paediatric MDR TB among cases with available DST results and the trend of DST coverage of paediatric TB cases was stable over the study period.

The highest number of paediatric MDR TB (including XDR TB) cases was reported by the United Kingdom (UK), followed by Germany, Romania and Sweden; nine countries did not report any paediatric MDR TB case during the study period (Figure 2). Countries with the highest number of paediatric MDR TB cases were countries with a large population such as Germany or the UK, countries with comparatively higher burden of TB such as Romania, or countries with a proportionately high migrant population such as Sweden. Countryspecific percentages of paediatric MDR TB among all paediatric TB cases ranged from $0.8 \%$ in Portugal to $16.7 \%$ in Luxembourg. 


\section{FIGURE 3}

Treatment outcome in paediatric tuberculosis cases by MDR status, European Union and European Economic Area, 2007-2014 $(\mathrm{n}=2,980)$

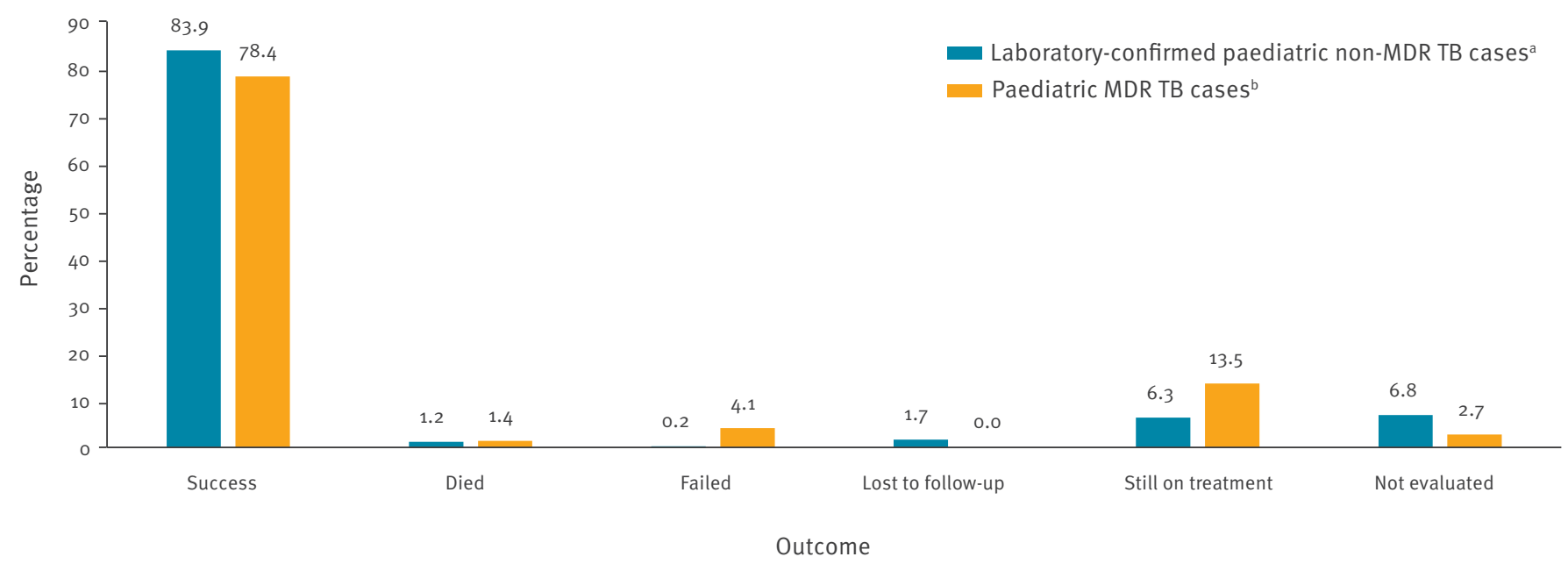

MDR: multidrug-resistant; TB: tuberculosis.

a Treatment outcome after 12 months, cohort 2007-14.

b Treatment outcome after 24 months, cohort 2007-13.

Non-MDR TB: susceptible, monoresistant and polyresistant TB; MDR TB: MDR TB including XDR TB.

MDR TB was associated with foreign origin ( $\mathrm{aOR}=1.73$; 95\% Cl: $1.12-2.67)$ and previous TB treatment $(\mathrm{aOR}=6.42 ; 95 \% \mathrm{Cl}: 3.24-12.75)$ (Table).

Successful treatment outcome after 24 months of treatment was reported for 58 of 74 paediatric MDR TB cases notified from 2007 to 2013 and successful treatment outcome after 12 months of treatment was reported for $2,438(83.9 \%)$ of 2,906 laboratory-confirmed paediatric non-MDR TB notified from 2007 to 2014 (Figure 3).

For paediatric MDR TB, treatment success was less frequently reported in children aged 5-9 years than in those younger than 5 years $(\mathrm{OR}=11.45 ; 95 \% \mathrm{Cl}$ : 1.24-106.04).

\section{Discussion}

We used surveillance data to describe the burden of MDR TB in children in 26 EU/EEA countries from 2007 to 2015 and to assess whether there are gaps in diagnosis and treatment of MDR TB in children. Our analysis showed that $2.9 \%$ of all paediatric TB cases with DST results were diagnosed with MDR or XDR TB. This is similar to the proportions reported from England and Wales (2.3\%) and the US (2.3\%) in children under 5 years of age $[24,25]$. Proportions of MDR TB were slightly higher in all notified TB cases (i.e. TB cases regardless of the age) in the EU/EEA, i.e. 4.1\% [4]. Only $21.9 \%$ of the reported paediatric TB cases in EU/EEA were laboratory-confirmed and could thus undergo DST. Of all notified TB cases in the EU/EEA, ca $80 \%$ were laboratory-confirmed in 2015 [4]. In other upper middle- and high-income countries, e.g. England and
Wales [24], the US [25,26] and Australia [27], the proportion of paediatric TB cases that is laboratory-confirmed is comparable. Thus, the challenges in other countries and World Health Organization (WHO) regions seem to be similar. In our analysis, almost half of the paediatric TB cases had extrapulmonary TB, a proportion that has also been described for other settings [9,28-32].

The high percentage of paediatric TB cases without laboratory confirmation raises the question of what the undiagnosed fraction of MDR TB is in children. The need for improvements in laboratory diagnosis of paediatric TB has been acknowledged and features prominently in the WHO roadmap for childhood tuberculosis [33]. A mathematical modelling study suggested far more MDR TB among children than diagnosed globally, with the burden of paediatric MDR TB being correlated with the overall MDR TB burden in a particular region [3].

DST results were reported for most paediatric TB cases who were laboratory-confirmed in the analysed EU/EEA countries. Accurate and comprehensive DST information is the cornerstone for prescribing adequate TB treatment. If such DST information is not available, treatment can only be based on the drug resistance pattern of the probable source case which, in low-incidence settings, is believed to be reflected in the resistance pattern of the secondary case [29]. In higher-incidence countries, more than half of the drug susceptibility patterns of household contacts may match the pattern of the purported source [34]. Moreover, the source case may not always be known. In children younger than 5 
Factors associated with paediatric multidrug-resistant tuberculosis in 26 European Union and European Economic Area countries reporting case-based drug-susceptibility data, 2007-2015 $(\mathrm{n}=3,378)$

\begin{tabular}{|c|c|c|c|c|c|c|}
\hline & \multicolumn{2}{|c|}{$\begin{array}{c}\text { Paediatric MDR TB } \\
\text { cases }\end{array}$} & \multicolumn{2}{|c|}{$\begin{array}{l}\text { Paediatric non-MDR TB } \\
\text { cases }\end{array}$} & \multirow{2}{*}{$\begin{array}{c}\text { Univariate logistic } \\
\text { regression } \\
\text { OR }(95 \% \mathrm{Cl})\end{array}$} & \multirow{2}{*}{$\begin{array}{c}\text { Multivariable logistic } \\
\text { regression } \\
\text { OR }(95 \% \mathrm{Cl})\end{array}$} \\
\hline & $\mathrm{n}$ & $\%$ & $\mathrm{n}$ & $\%$ & & \\
\hline Total & 98 & 2.9 & 3,280 & 97.1 & Not done & Not done \\
\hline \multicolumn{7}{|c|}{ Age groups $(n=3,378)$} \\
\hline $0-4$ years & 26 & 26.5 & 1,156 & 35.2 & 1 & Not included \\
\hline $5-9$ years & 22 & 22.5 & 577 & 17.6 & $1.69(0.95-3.02)$ & Not included \\
\hline $10-14$ years & 50 & 51.0 & 1,547 & 47.2 & $1.43(0.89-2.32)$ & Not included \\
\hline \multicolumn{7}{|l|}{$\operatorname{Sex}(n=3,372)$} \\
\hline Male & 41 & 41.8 & 1,567 & 47.9 & 1 & Not included \\
\hline Female & 57 & 58.2 & 1,707 & 52.1 & $1.28(0.85-1.92)$ & Not included \\
\hline \multicolumn{7}{|l|}{ Origin $(n=3,315)$} \\
\hline Native & 53 & 54.1 & 2,163 & 67.2 & 1 & 1 \\
\hline Foreign & 45 & 45.9 & 1,054 & 32.8 & $1.74(1.16-2.61)$ & $1.73(1.12-2.67)$ \\
\hline \multicolumn{7}{|c|}{ TB treatment history $(n=2,949)$} \\
\hline New & 76 & 87.4 & 2,798 & 97.8 & 1 & 1 \\
\hline Previously treated & 11 & 12.6 & 64 & 2.2 & $6.33(3.21-12.48)$ & $6.42(3.24-12.75)$ \\
\hline \multicolumn{7}{|c|}{ Site of disease $(n=3,374)$} \\
\hline Pulmonary & 68 & 69.4 & 2,448 & 74.7 & 1 & Not included \\
\hline Extrapulmonary & 30 & 30.6 & 828 & 25.3 & $1.30(0.84-2.02)$ & Not included \\
\hline
\end{tabular}

$\mathrm{Cl}$ : confidence interval; MDR: multidrug-resistant; OR: odds ratio; TB: tuberculosis.

years in the US, only $53 \%$ had a known source case and could thus be treated adequately without information on drug susceptibility [25].

In line with other studies, we found foreign origin and previous TB treatment history to be significantly associated with paediatric MDR TB $[30,35]$. A history of previous TB treatment suggests potentially preventable acquired drug resistance or inadequate treatment of primary drug-resistant TB, while the frequency of MDR TB among children with foreign origin reflects the prevalence of MDR TB in the respective country of origin.

In the EU/EEA, most paediatric MDR/XDR TB cases notified in 2007-2013 were successfully treated, with one death and two failed treatments reported. This indicates that in EU/EEA countries, the main challenge lies in the identification of paediatric MDR/XDR TB cases and that once cases have been detected, means and expertise are sufficient to ensure adequate treatment. The treatment success rate was lower than in South Africa (82-90\%) [35,36] and Israel (97.8\%) [37]. In our study, half of the successful treatment outcomes in paediatric MDR TB cases were in the age group of 10-14 year-olds, which can be attributed to increasing tolerance of the TB treatment with age [38]. Only in the age group of 5-9 year-olds, a significantly lower percentage of paediatric MDR TB cases with treatment success was identified, although the analysis was limited by the small number of cases.

\section{Limitations}

An important limitation of the study is that information on TB contact history and preventive treatment of TB contacts is not collected at EU/EEA level. Therefore, epidemiological links cannot be identified and the effectiveness of the preventive TB treatment cannot be assessed. The incompleteness of reported TB notification data, the differences in accuracy of laboratory diagnosis of paediatric TB between EU/EEA countries and the heterogeneity of the TB situation in the EU/EEA should be taken into account when interpreting the results.

\section{Conclusions}

The burden of MDR TB in children in the EU/EEA appears low and stable over time. Laboratory confirmation of paediatric TB remains a challenge in EU/EEA and may lead to an underestimation of the real burden of MDR TB among children. Improvements in the laboratory diagnosis of paediatric TB are needed for early detection and adequate treatment of MDR TB. Children previously treated for TB and children of foreign origin may need to be given higher attention regarding MDR TB.

\section{Acknowledgements}

The authors would like to thank the following nominated ECDC Operational Contact Points for TB surveillance from the $26 \mathrm{EU} / \mathrm{EEA}$ Member States included in this analysis: Peter Henrik Andersen, Margaret Trude Arnesen, Bernhard Benka, Thorsteinn Blondal, Domnica Ioana Chiotan, Edita Davidavičienė, Irene Demuth, Raquel Duarte, Lena Fiebig, 
Ourania Kalkouni, Maria Koliou, Maria KorzeniewskaKosela, Gábor Kovács, Maeve Lalor, Dace Mihalovska, Joan O’Donnell, Analita Pace Asciak, Erika Slump, Hanna Soini, Ivan Solovič, Petra Svetina, Tonka Varleva, Piret Viiklepp, Kate Vulāne, Jiři Wallenfels and Maryse Wanlin.

\section{Conflict of interest}

None declared.

\section{Authors' contributions}

CK contributed to the study design, performed the data analysis and wrote the first draft of the manuscript.

MvdB contributed to the study design and contributed to further versions of the manuscript and approved the final version before submission. PZ contributed to the study design, and contributed to further versions of the manuscript and approved the final version before submission. MvdW contributed to the study design and data analysis, and contributed to further versions of the manuscript and approved the final version before submission.

\section{References}

1. World Health Organization (WHO). The end TB strategy: Global strategy and targets for tuberculosis prevention, care and control after 2015. Geneva: WHO; 2014. Available from: http:// www.who.int/tb/strategy/End_TB_Strategy.pdf?ua=1

2. World Health Organization (WHO). Global tuberculosis report 2016. Geneva: WHO; 2016. Available from: http://apps.who.int/ iris/bitstream/10665/250441/1/9789241565394-eng.pdf?ua=1

3. Dodd PJ, Sismanidis C, Seddon JA. Global burden of drugresistant tuberculosis in children: a mathematical modelling study. Lancet Infect Dis. 2016;16(10):1193-201. https://doi. org/10.1016/S1473-3099(16)30132-3 PMID: 27342768

4. European Centre for Disease prevention and Control (ECDC)/ World Health Organization Regional Office for Europe (WHO/ Europe). Tuberculosis surveillance and monitoring in Europe 2017. Stockholm: ECDC; 2017. Available from: https://ecdc. europa.eu/sites/portal/files/documents/ecdc-tuberculosissurveillance-monitoring-Europe-2017-WEB.pdf

5. Cuevas LE, Browning R, Bossuyt $P$, Casenghi M, Cotton MF, Cruz AT, et al. Evaluation of tuberculosis diagnostics in children: 2. Methodological issues for conducting and reporting research evaluations of tuberculosis diagnostics for intrathoracic tuberculosis in children. Consensus from an expert panel. J Infect Dis. 2012;205(Suppl 2):S209-15. https:// doi.org/10.1093/infdis/jir879 PMID: 22476719

6. Dunn JJ, Starke JR, Revell PA. Laboratory Diagnosis of Mycobacterium tuberculosis Infection and Disease in Children. J Clin Microbiol. 2016;54(6):1434-41. https://doi.org/10.1128/ JCM.03043-15 PMID: 26984977

7. Jenkins HE, Tolman AW, Yuen CM, Parr JB, Keshavjee S, PérezVélez CM, et al. Incidence of multidrug-resistant tuberculosis disease in children: systematic review and global estimates. Lancet. 2014;383(9928):1572-9. https://doi.org/10.1016/ S0140-6736(14)60195-1 PMID: 24671080

8. Chiang SS, Swanson DS, Starke JR. New Diagnostics for Childhood Tuberculosis. Infect Dis Clin North Am. 2015;29(3):477-502. https://doi.org/10.1016/j.idc.2015.05.011 PMID: 26188605

9. Lopez Avalos GG, Prado Montes de Oca E. Classic and new diagnostic approaches to childhood tuberculosis. J Trop Med. 2012;2012:818219.

10. Clinical and Laboratory Standards Institute (CLSI). Laboratory detection and identification of mycobacteria. 1st ed. CLSI document M48-A. Wayne, PA: CLSI; 2008.

11. Horsburgh CR Jr, Barry CE 3rd, Lange C. Treatment of Tuberculosis. N Engl J Med. 2015;373(22):2149-6o. https://doi. org/10.1056/NEJMra1413919 PMID: 26605929

12. World Health Organization (WHO). Treatment of tuberculosis. Guidelines. 4th ed. Geneva: WHO; 2010. Available from: http:// apps.who.int/iris/bitstream/10665/44165/1/9789241547833_ eng.pdf?ua $=1 \& u a=1$
13. World Health Organization (WHO). Guidance for national tuberculosis programmes on the management of tuberculosis in children. 2nd ed. Geneva: WHO; 2014. Available from: http:// apps.who.int/iris/bitstream/10665/11236o/1/9789241548748_ eng.pdf?ua=1

14. Piccini P, Chiappini E, Tortoli E, de Martino M, Galli L. Clinical peculiarities of tuberculosis. BMC Infect Dis. 2014;14(Suppl 1):S4. https://doi.org/10.1186/1471-2334-14-S1-S4 PMID: 24564419

15. Morris SK, Demers AM, Lam R, Pell LG, Giroux RJ, Kitai I. Epidemiology and clinical management of tuberculosis in children in Canada. Paediatr Child Health. 2015;20(2):83-8. https://doi.org/10.1093/pch/20.2.83 PMID: 25838781

16. Yuen CM, Rodriguez CA, Keshavjee S, Becerra MC. Map the gap: missing children with drug-resistant tuberculosis. Public Health Action. 2015;5(1):45-58. https://doi.org/10.5588/ pha.14.0100 PMID: 26400601

17. Mukherjee JS, Joseph JK, Rich ML, Shin SS, Furin JJ, Seung $\mathrm{KJ}$, et al. Clinical and programmatic considerations in the treatment of MDR-TB in children: a series of 16 patients from Lima, Peru. Int J Tuberc Lung Dis. 2003;7(7):637-44. PMID: 12870684

18. Padayatchi N, Bamber S, Dawood H, Bobat R. Multidrugresistant tuberculous meningitis in children in Durban, South Africa. Pediatr Infect Dis J. 2006;25(2):147-50. https://doi. org/10.1097/01.inf.0000199314.88063.4C PMID: 16462292

19. Seddon JA, Donald PR, Vlok GJ, Schaaf HS. Multidrug-resistant tuberculosis of the spine in children--characteristics from a high burden setting. J Trop Pediatr. 2012;58(5):341-7. https:// doi.org/10.1093/tropej/fmr104 PMID: 22170512

20. Shah I. Multidrug-resistant tuberculosis in children from 2003 to 2005: a brief report. Indian J Med Microbiol. 2012;30(2):20811. https://doi.org/10.4103/0255-0857.96694 PMID: 22664439

21. Mignone F, Codecasa LR, Scolfaro C, Raffaldi I, Lancella $\mathrm{L}$, Ferrarese $\mathrm{M}$, et al. The spread of drug-resistant tuberculosis in children: an Italian case series. Epidemiol Infect. 2014;142(10):2049-56. https://doi.org/10.1017/ So950268813003191 PMID: 24480079

22. Achar J, Berry C, Herboczek K, Parpieva N, Tillyashaykhov MN, Tigay ZN, et al. Multidrug-Resistant Tuberculosis in Child Successfully Treated with 9-Month Drug Regimen. Emerg Infect Dis. 2015;21(11):2105-6. https://doi.org/10.3201/eid2111.151119 PMID: 26488556

23. European Commission. Commission Implementing Decision of 8 August 2012 amending Decision 2002/253/EC laying down case definitions for reporting communicable diseases to the Community network under Decision No 2119/98/EC of the European Parliament and of the Council. Luxembourg: Publications Office of the European Union. Official Journal. L262 2012. Available from: http://eur-lex.europa.eu/ legal-content/EN/TXT/?uri=0J\%3AL\%3A2012\%3A262\%3ATOC

24. Abubakar I, Laundy MT, French CE, Shingadia D. Epidemiology and treatment outcome of childhood tuberculosis in England and Wales: 1999-2006. Arch Dis Child. 2008;93(12):1017-21. https://doi.org/10.1136/adc.2008.139543 PMID: 18562450

25. Pang J, Teeter LD, Katz DJ, Davidow AL, Miranda W, Wall K, et al. Epidemiology of tuberculosis in young children in the United States. Pediatrics. 2014;133(3):e494-504. https://doi. org/10.1542/peds.2013-2570 PMID: 24515517

26. Menzies HJ, Winston CA, Holtz TH, Cain KP, Mac Kenzie WR. Epidemiology of tuberculosis among US- and foreign-born children and adolescents in the United States, 1994-2007. Am J Public Health. 2010;100(9):1724-9. https://doi.org/10.2105/ AJPH.2009.181289 PMID: 20634457

27. Teo SS, Tay EL, Douglas P, Krause VL, Graham SM. The epidemiology of tuberculosis in children in Australia, 20032012. Med J Aust. 2015;203(11):440. https://doi.org/10.5694/ mja15.00717 PMID: 26654612

28. Ritz N, Curtis N. Novel concepts in the epidemiology, diagnosis and prevention of childhood tuberculosis. Swiss Med Wkly. 2014;144:W14000. PMID: 25207918

29. Faddoul D. Childhood tuberculosis: an overview. Adv Pediatr. 2015;62(1):59-90. https://doi.org/10.1016/j.yapd.2015.04.001 PMID: 26205109

30. Hamzaoui A, Yaalaoui S, Tritar Cherif F, Slim Saidi L, Berraies A. Childhood tuberculosis: a concern of the modern world. Eur Respir Rev. 2014;23(133):278-91. https://doi. org/10.1183/09059180.00005314 PMID: 25176964

31. Maltezou HC, Spyridis P, Kafetzis DA. Extra-pulmonary tuberculosis in children. Arch Dis Child. 2000;83(4):342-6. https://doi.org/10.1136/adc.83.4.342 PMID: 10999874

32. Zumla A, Raviglione M, Hafner R, von Reyn CF. Tuberculosis. N Engl J Med. 2013;368(8):745-55. https://doi.org/10.1056/ NEJMra1200894 PMID: 23425167 
33. World Health Organization (WHO). Roadmap for childhood tuberculosis. Geneva: WHO; 2013. Available from: http://apps. who.int/iris/bitstream/10665/89506/1/9789241506137_eng. pdf

34. Shah NS, Yuen CM, Heo M, Tolman AW, Becerra MC. Yield of contact investigations in households of patients with drugresistant tuberculosis: systematic review and meta-analysis. Clin Infect Dis. 2014;58(3):381-91. https://doi.org/10.1093/cid/ cit643 PMID: 24065336

35. Seddon JA, Hesseling AC, Willemse M, Donald PR, Schaaf HS. Culture-confirmed multidrug-resistant tuberculosis in children: clinical features, treatment, and outcome. Clin Infect Dis. 2012;54(2):157-66. https://doi.org/10.1093/cid/cir772 PMID: 22052896

36. Seddon JA, Hesseling AC, Godfrey-Faussett P, Schaaf HS. High treatment success in children treated for multidrugresistant tuberculosis: an observational cohort study. Thorax. 2014;69(5):458-64. https://doi.org/10.1136/ thoraxjnl-2013-203900 PMID: 24064441

37. Mor Z, Cedar N, Pinsker G, Bibi H, Grotto I. Childhood tuberculosis in Israel: epidemiological trends and treatment outcomes, 1999-2010. Eur Respir J. 2013;41(5):1157-62. https://doi.org/10.1183/09031936.00033912 PMID: 23018912

38. Frydenberg AR, Graham SM. Toxicity of first-line drugs for treatment of tuberculosis in children: review. Trop Med Int Health. 2009;14(11):1329-37. https://doi.org/10.1111/j.13653156.2009.02375.x PMID: 19735381

\section{License and copyright}

This is an open-access article distributed under the terms of the Creative Commons Attribution (CC BY 4.0) Licence. You may share and adapt the material, but must give appropriate credit to the source, provide a link to the licence, and indicate if changes were made.

This article is copyright of the authors, 2017. 